\title{
MC3 Mucoepidermoid carcinoma cell line enriched cancer stem-like cells following chemotherapy
}

\author{
LOUQIANG ZHANG ${ }^{1}$, LONGJIANG LI ${ }^{2,3}$, YIN WANG ${ }^{1}$, YING LIU ${ }^{2,3}$ and CHUNJIE LI ${ }^{2,3}$ \\ ${ }^{1}$ Department of Stomatology, Tianjin Medical University General Hospital, Tianjin 300052; \\ ${ }^{2}$ State Key Laboratory of Oral Diseases and ${ }^{3}$ Department of Head and Neck Oncology Surgery, \\ West China Hospital of Stomatology, Sichuan University, Chengdu, Sichuan 610041, P.R. China
}

Received July 14, 2013; Accepted January 27, 2014

DOI: $10.3892 / 01.2014 .1902$

\begin{abstract}
Mucoepidermoid carcinoma (MEC) is common in human salivary glands. Surgery is the preferred treatment method for MEC and chemotherapy is often administered following surgery as an adjuvant cancer treatment; however, chemotherapy does not completely prevent tumor recurrence. Emerging evidence has indicated the existence of cancer stem-like (CSL)-cells in tumors. CSL-cells are important in the development, invasion and drug resistance of carcinomas. The present study aimed to investigate whether chemotherapy enriched the CSL-cells in the MEC cell line of MC3 using 5-fluorouracil (5-Fu). The MC3 cells were treated with 5-Fu, which enhanced the spherogenesis and vitality of the cells and upregulated the pluripotency gene, octamer-binding transcription factor 4. Side population analysis demonstrated that the proportion of CSL-cells also increased. These findings showed that compared with other types of cancer cells, chemotherapy was unable to effectively kill the CSL-cells resulting in an enriched CSL-cell subpopulation with a higher resistance to chemotherapy, which may have been key the recurrence of MEC.
\end{abstract}

\section{Introduction}

Mucoepidermoid carcinoma (MEC) is common in human salivary glands. Poorly differentiated MEC is a lethal malignancy that readily invades nearby tissues and is likely to recur (1). Conventional surgery is the most common treatment method for MEC, however, often results in devastating functional and cosmetic consequences. In order to kill residual tumor cells and prevent the recurrence of MEC, chemotherapy is required

Correspondence to: Dr Louqiang Zhang, Department of Stomatology, Tianjin Medical University General Hospital, 154 Anshan Road, Tianjin 300052, P.R. China

E-mail: louqiang98@163.com

Key words: cancer stem-like cells, mucoepidermoid carcinoma, octamer-binding transcription factor 4 , cluster of differentiation 44 , 5-fluorouracil following surgery. The chemotherapeutic agent, 5-fluorouracil $(5-\mathrm{Fu})$, is commonly used; however, chemotherapy is unable to kill all of the remaining tumor cells or prevent the recurrence of MEC. The underlying mechanisms of MEC recurrence following chemotherapy have not yet been investigated.

Cancer stem-like (CSL)-cells are a rare population of cancer cells exhibiting stem cell properties, constituting a reservoir of self-sustaining cells with an exclusive ability to self-renew and maintain the tumor. CSL-cells were identified first in acute myeloid leukemia (2) followed by solid tumors and subsequently breast cancer in 2003 (3). CSL-cells have been isolated from a variety of human malignancies, including leukemia $(2,4)$, breast cancer $(3,5)$, brain tumors $(6-8)$, hepatocellular carcinoma (9), pancreatic (10) and colorectal cancers $(11,12)$, melanomas (13), prostate cancer (14) and bone sarcomas (15). CSL-cells are significant in tumor formation and growth (16-18). Potentially quiescent CSL-cells, which are vital and capable of repopulating under cancer therapies, may be a source of recurrence and drug resistance $(3,19)$.

The present study aimed to investigate the effects of chemotherapy on the MC3 MEC cell line and the potential roles of CSL-cells in recurrent MEC following chemotherapy.

\section{Materials and methods}

Cell line and culture. The MC3 MEC cell line was provided and conserved at the State Key Laboratory of Oral Diseases, Sichuan University (Chengdu, China). The MC3 cells were maintained in a serum-containing medium composed of RPMI-1640 (Hyclone, Logan, UT, USA) and 10\% fetal bovine serum (FBS; Gibco-BRL, Grand Island, NY, USA). The cells were incubated at $37^{\circ} \mathrm{C}$ in a $5 \% \mathrm{CO}_{2}$ humidified atmosphere and passaged once every three days.

MC3 cell culture in 5-Fu-containing medium. The MC3 cells were incubated in a serum-containing medium composed of RPMI-1640, 10\% FBS and 1 peak plasma concentration of $100 \mu \mathrm{g} / \mathrm{ml} \mathrm{5-Fu} \mathrm{(20)} \mathrm{at} 37^{\circ} \mathrm{C}$ in a $5 \% \mathrm{CO}_{2}$ humidified atmosphere for $24 \mathrm{~h}$.

Soft agarose assays of clone formation. The 5-Fu-treated and parent MC3 cells were seeded in 24-well plates. Low 
melting-point agarose $(0.3 \mathrm{ml}, 0.6 \%$; Type VII, Sigma-Aldrich, St. Louis, MO, USA) was poured into each well and $0.3 \mathrm{ml}$ $(0.35 \%)$ agarose containing 100 cells was subsequently added to each well. The cells were incubated following the solidification of agarose at room temperature. The number of clones containing $>50$ cells was counted under a microscope after ten days and the cloning efficiency was calculated using the following formula: Colony formation rate $(\%)=$ no. of clones/no. of cells incubated x 100.

MTT assay. The 5-Fu-treated and parent MC3 cells were seeded in 96-well plates, each well contained 2,000 cells and was cultured in complete RPMI-1640 medium with $10 \%$ FBS. The cell viability was measured using the MTT assay (Sigma-Aldrich). The optical density (OD) values were obtained using a microplate reader (ThermoElectron 3001 Varioskan Flash; USA) on days one, three, five, seven and nine.

Quantitative polymerase chain reaction ( $q P C R$ ). $\mathrm{qPCR}$ was performed using the $\mathrm{SYBR}^{\circledR}$ Green reporter to detect the expression of genes, cluster of differentiation (CD) 44 and octamer-binding transcription factor 4 (Oct4). The primer sequences are summarized in Table I. The cells were harvested and RNA was extracted from the 5-Fu-treated and parent MC3 cells using TRIzol reagent (Invitrogen Life Technologies, Carlsbad, CA, USA), then reverse-transcribed into cDNA using PrimeScript RT reagent kit (Takara, Dalian, China) according to the manufacturer's instructions. qPCR was performed according to the standard protocol of the SYBR Premix Ex Taq $^{\text {TM }}$ II kit (Takara) on an ABI 7300 Real Time PCR system (Applied Biosystems, Foster City, CA, USA). To quantify the changes in gene expression, the $\Delta \Delta \mathrm{Ct}$ method was used to calculate the relative fold changes following normalization using the internal reference gene, GAPDH.

Immunocytochemistry. The 5-Fu-treated and parent MC3 cells were plated on glass coverslips at $37^{\circ} \mathrm{C}$ overnight, washed twice with PBS, and immunostained for CD44, Oct4 and the isotype control. The primary antibodies included rat monoclonal anti-CD44 (dilution 1:100; eBiosciences, San Diego, CA, USA) and rabbit monoclonal anti-Oct4 (dilution 1:50; Bioworld Technology, Minneapolis, MN, USA). The secondary antibodies included goat anti-rat IgG and goat anti-rabbit IgG (dilutions 1:50; Bios, Beijing, China). The intensity of 3,3'-diaminobenzidine was analyzed using the immunohistochemical Avidin Biotin Complex (ABC) method (15). Images were captured using a Nikon eclipse 80i microscope (Nikon Corp., Tokyo, Japan).

Fluorescence-activated cell sorting (FACS) of CD44 and Oct4. The 5-Fu-treated and parent MC 3 cells were trypsinized into solitary cell suspensions. The cells were counted, washed twice with PBS, resuspended in ice-cold PBS (supplemented with 2\% FBS) and labeled with antibodies specific for human cells, such as rat monoclonal anti-CD44 antibody. The cells were incubated with their antibodies for $30 \mathrm{~min}$ at $4^{\circ} \mathrm{C}$ in the dark. The unbound antibodies were removed by washing twice with PBS. The fluorescein isothiocyanate (FITC)-labeled secondary antibody was added to the cell suspension and incubated for $30 \mathrm{~min}$ at $4^{\circ} \mathrm{C}$ in the dark. The cells were washed twice with PBS and FACS analysis (BD Biosciences, San Jose, CA, USA) was performed.

The 5-Fu-treated and parent MC3 cells were fixed and perforated, resuspended in ice-cold PBS and labeled with antibodies specific for human cells, such as rabbit monoclonal anti-Oct4 antibody. The cells were incubated with their antibodies for $30 \mathrm{~min}$ at $4^{\circ} \mathrm{C}$ in the dark. The unbound antibodies were removed by washing twice with PBS. The FITC-labeled secondary antibody was added to the cell suspension and incubated for $30 \mathrm{~min}$ at $4^{\circ} \mathrm{C}$ in the dark. The cells were washed twice with PBS and FACS analysis was performed.

Culture of the cells in serum-free medium. The 5-Fu-treated and parent MC3 cells were washed three times with PBS to remove all traces of FBS. The cells were placed in serum-free Dulbecco's modified Eagle's medium (DMEM)/F12 (Hyclone), which was composed of $20 \mathrm{ng} / \mathrm{ml}$ basic fibroblast growth factor (PeproTech, Rocky Hill, NJ, USA), 20 ng/ml epidermal growth factor (PeproTech), $1 \mathrm{mg} / \mathrm{ml}$ insulin (Sigma-Aldrich) and 2\% B27 (Invitrogen Life Technologies) at a density of $1 \times 10^{2} / \mathrm{ml}$. The cell suspensions $(200 \mu \mathrm{l})$ were plated onto ultra-low attachment 96-well plates. The number of clones containing $>50$ cells was counted under a microscope on day seven and the cloning efficiency was calculated using the following formula: Colony formation rate $(\%)=$ no. of clones/no. of cells incubated x100.

FACS analysis of side population (SP) cells. SP cell analysis was based on a previously described method (21) with certain modifications. Briefly, cells were trypsinized and resuspended in PBS with $2 \%$ FBS at a density of $1 \times 6^{10} / \mathrm{ml}$. Verapamil (Sigma-Aldrich) at a final concentration of $50 \mu \mathrm{g} / \mathrm{ml}$ was added to the control group. After $10 \mathrm{~min}, 10 \mu \mathrm{g} / \mathrm{ml}$ Hoechst 33342 (Sigma-Aldrich) was added to the cell suspension, this was incubated in the dark for $90 \mathrm{~min}$, centrifuged and resuspended in ice-cold PBS containing 2\% FBS. Propidium iodine ( $2 \mu \mathrm{g} / \mathrm{ml}$; Sigma-Aldrich) was added to separate the dead cells. Analysis and sorting were performed on a BD FACSAria.

Statistical analysis. Statistical analyses were performed with SPSS software, version 11.5 (SPSS, Inc., Chicago, IL, USA). All quantified data present the means of at least three samples and error bars represent the standard deviation. Student's t-test was used to determine the statistical differences between the experimental and control groups. $\mathrm{P}<0.05$ was considered to indicate a statistically significant difference.

\section{Results}

5-Fu-treated cells. The MC3 cells were exposed to 5-Fu for $24 \mathrm{~h}$ resulting in a large number of cell deaths. The dead cells were suspended in the medium and the surviving cells adhered to the plate wall. The viable cells were collected for subsequent experiments.

5-Fu-treated cells exhibit a higher cloning efficiency. The 5-Fu-treated and parent MC3 cells underwent the agarose colony formation experiments and showed that the cloning ratio of 5-Fu-treated cells $(33.47 \pm 1.30 \%)$ was significantly 
Table I. Primer sequences for quantitative polymerase chain reaction.

\begin{tabular}{lcc}
\hline Gene & Upstream primer & Downstream primer \\
\hline CD44 & 5'-gagcagcacttcaggaggttaca-3' & 5'-agtggtagcagggattctgtctg-3' \\
Oct4 & 5'-gcacaacgagaggatttgagg-3' & 5'-agggaaagggaccgaggagta-3' \\
GAPDH & 5'-ctttggtatcgtggaaggactc-3' & 5'-gtagaggcagggatgatgttct-3'
\end{tabular}

CD44, cluster of differentiation 44; Oct4, octamer-binding transcription factor 4.

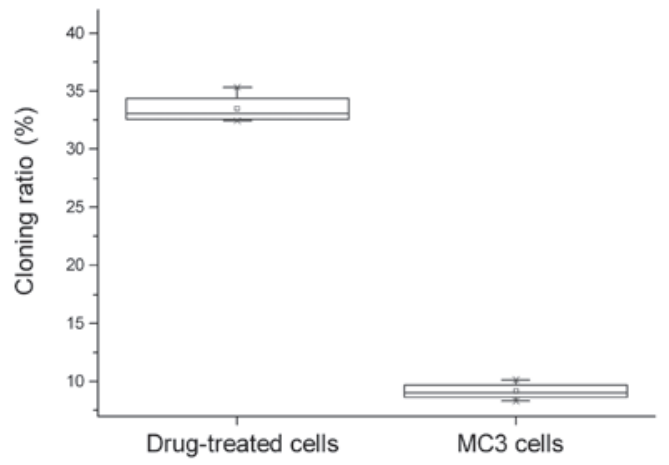

Figure 1. Cloning ratio of 5-Fu (drug)-treated and parent MC3 cells in soft agarose. The cloning ratio of 5-Fu-treated cells was significantly higher than the parent MC3 cells $(\mathrm{P}<0.05) .5-\mathrm{Fu}, 5$-fluorouracil.

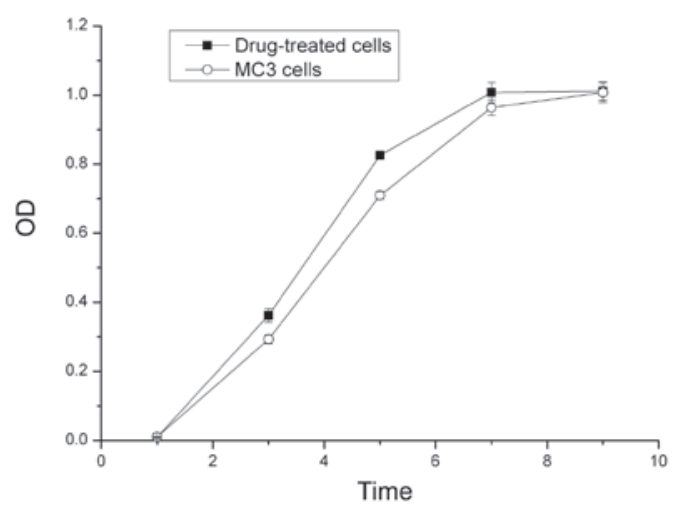

Figure 2. Growth curves of 5-Fu (drug)-treated cells and parent MC3 cells, the proliferative ability of 5-Fu-treated cells was significantly higher than the parent MC3 cells $(\mathrm{P}<0.05)$. 5-Fu, 5-fluorouracil; OD, optical density.

higher compared with the parent MC3 cells $(9.14 \pm 0.747 \%$, $\mathrm{P}<0.05$; Fig. 1).

Growth curves of the cells. The OD values from the MTT assay were used to construct growth curves. The proliferative ability of the 5-Fu-treated cells was higher compared with the parent MC3 cells in the first seven days. The 5-Fu-treated cells reached the plateau phase on day seven, whereas the parent MC3 cells reached the plateau phase on day nine $(\mathrm{P}<0.05$; Fig. 2).

qPCR analysis. The gene expression status of CD44 and Oct4 were compared between the 5-Fu-treated and the parent MC3 cells via $\mathrm{qPCR}$. The results revealed that the reference gene, GAPDH, was stably expressed in all the samples, and CD44

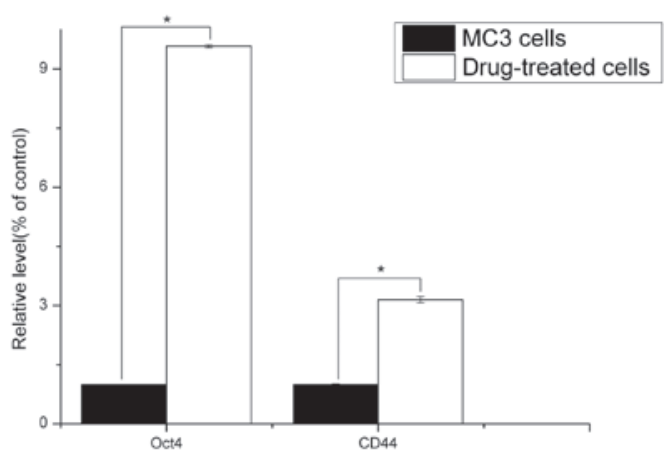

Figure 3. Gene expression examined by quantitative polymerase chain reaction. The expression of CD44 and Oct4 was statistically different between the 5-Fu (drug)-treated and parent $\mathrm{MC} 3$ cells $(\mathrm{P}<0.05)$. 5-Fu, 5-fluorouracil; Oct4, octamer-binding transcription factor 4; CD44, cluster of differentiation 44. ${ }^{*} \mathrm{P}<0.05$ parent MC3 cells vs. 5 -Fu treated cells

and Oct4 were significantly expressed in the 5-Fu-treated cells compared with the parent MC3 cells ( $\mathrm{P}<0.05$; Fig. 3$)$.

CD44 and Oct4 protein expression. Immunocytochemistry assays were used to analyze the expression of CD44 and Oct4 in 5-Fu-treated and parent MC3 cells. The expression levels of CD44 and Oct4 in 5-Fu-treated cells were higher compared with the parent MC3 cells. CD44 was expressed in the cell membrane and cytoplasm, whereas Oct4 was expressed in the nucleus (Fig. 4).

Furthermore, the expression of CD44 and Oct4 was analyzed by FACS. According to three independent experiments, the expression levels of CD44 and Oct4 were $99.50 \pm 0.30$ and $14.60 \pm 0.36 \%$, respectively in the 5-Fu-treated cells, and $14.47 \pm 0.15$ and $1.37 \pm 0.06 \%$, respectively, in the MC3 cells (Fig. 5). The expression levels of CD44 and Oct4 were significantly different between the two cell populations $(\mathrm{P}<0.05)$.

Spheroid cells in the serum-free medium. The 5-Fu-treated and parent MC3 cells that were incubated in serum-free medium for one day revealed multicellular spheroids. Spheroids were apparent following cell culture in serum-free medium for four days (Fig. 6). The number of cells in the spheroids gradually increased in a time-dependent manner and on day seven spherical bodies comprising of dozens of cells were observed. The number of spherical bodies increased by $>20 \%$ following treatment with $5-\mathrm{Fu}$. When the spheroid cells were cultured in RPMI-1640 with 10\% FBS they became adherent. These findings identified that under stem cell culture conditions, MC3 and 5-Fu-treated cells 


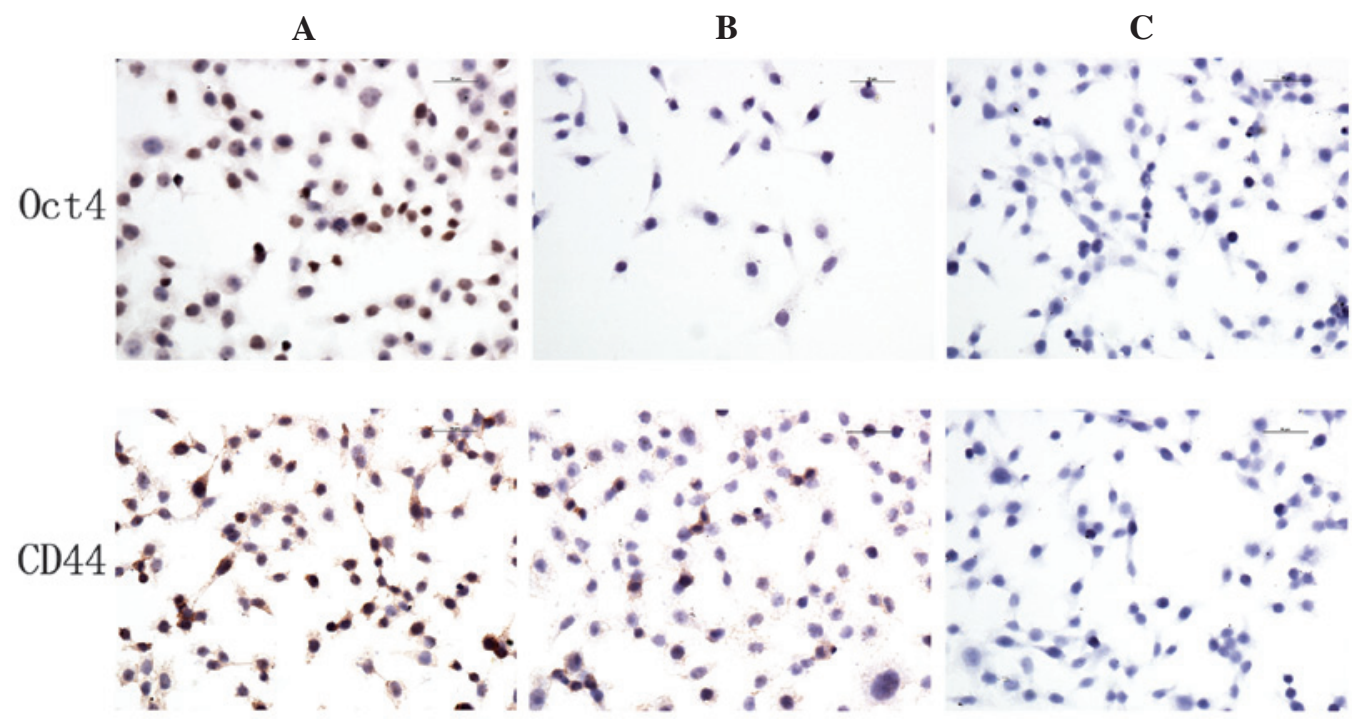

Figure 4. Immunocytochemistry assays of Oct4 and CD44 in (A) 5-Fu-treated and (B) parent MC3 cells. The expression of CD44 and Oct4 in the 5-Fu-treated cells was higher than in the parent MC3 cells. (C) Expression of Oct4 and CD44 in the isotype control. 5-Fu, 5-fluorouracil; Oct4, octamer-binding transcription factor 4; CD44, cluster of differentitation 44

A

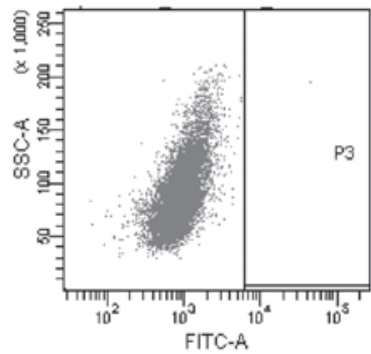

0 ct4

CD44

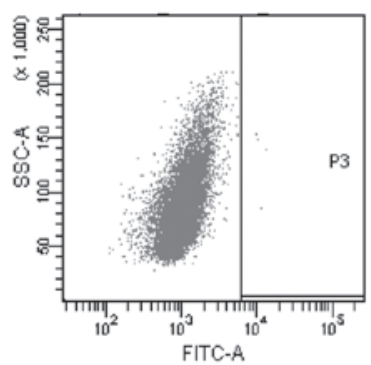

B
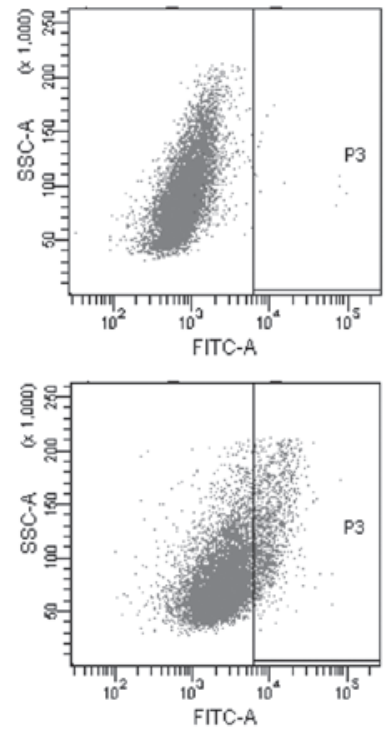

C
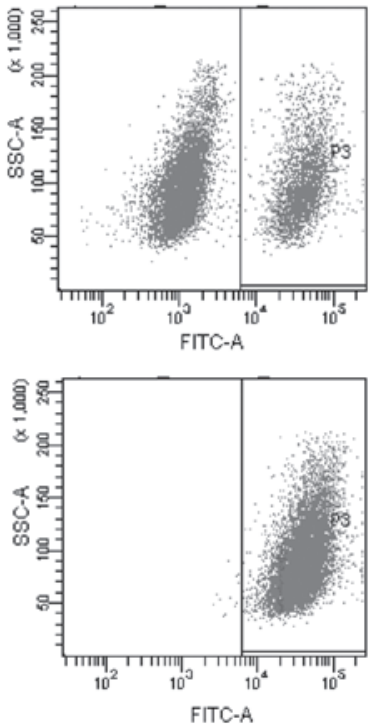

Figure 5. FACS analysis of Oct4 and CD44 in the (A) blank control, (B) parent MC3 and (C) 5-Fu-treated cells. The percentage of Oct4+ and CD44+ phenotype in the parent MC3 cells was $1.37 \pm 0.06$ and $14.47 \pm 0.15 \%$, respectively. The percentage of Oct4+ and CD44+ phenotype in the 5-Fu-treated cells was $14.60 \pm 0.36 \%$ and $99.50 \pm 0.30 \%$, respectively. FACS, fluorescence-activated cell sorting; 5-Fu, 5-fluorouracil; Oct4, octamer-binding transcription factor 4; CD44, cluster of differentitation 44; FITC-A, fluorescein isothiocyanate labeled antibody.

A

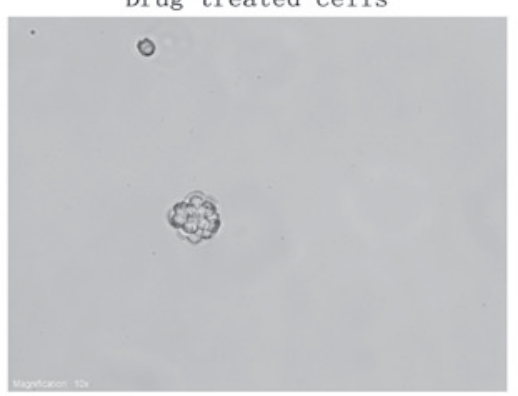

B

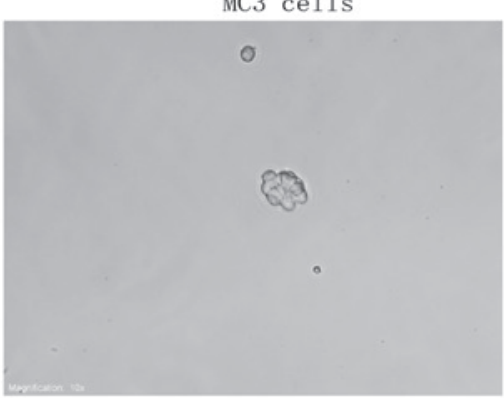

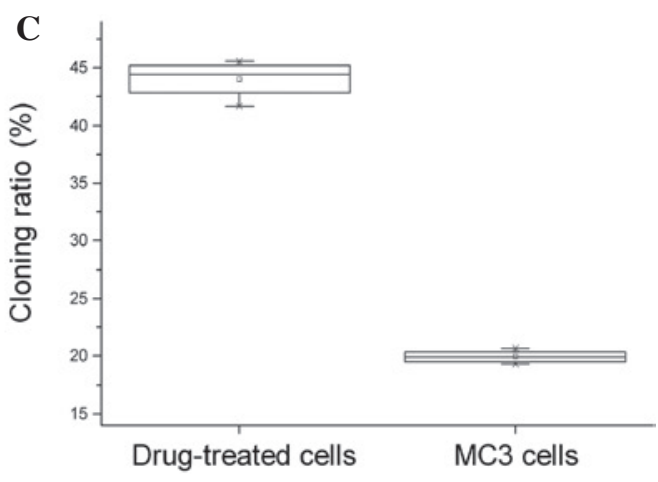

Figure 6. Spheroids of (A) 5-Fu (drug)-treated and (B) parent MC3 cells in serum-free medium. (C) The cloning (spheroids) ratio of 5-Fu-treated and MC3 cells was $44.02 \pm 1.71$ and $19.94 \pm 0.57 \%$, respectively $(\mathrm{P}<0.05)$. 5-Fu, 5 -fluorouracil. 
no Verapami 1
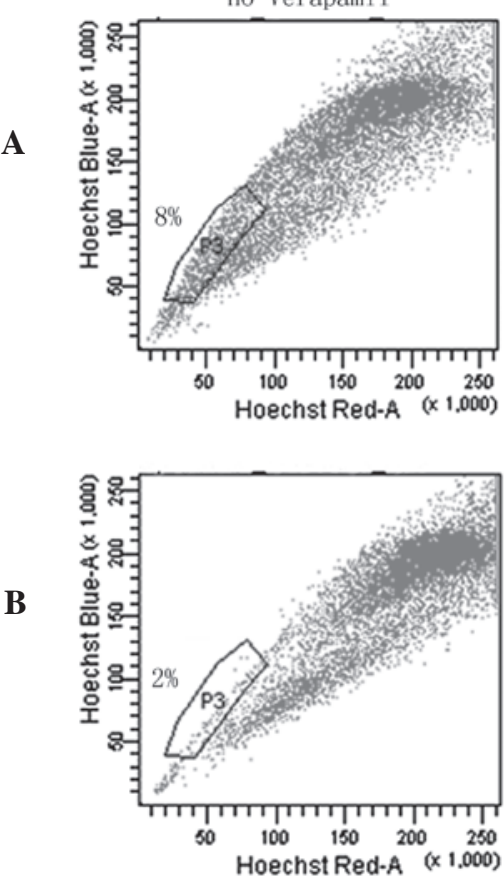
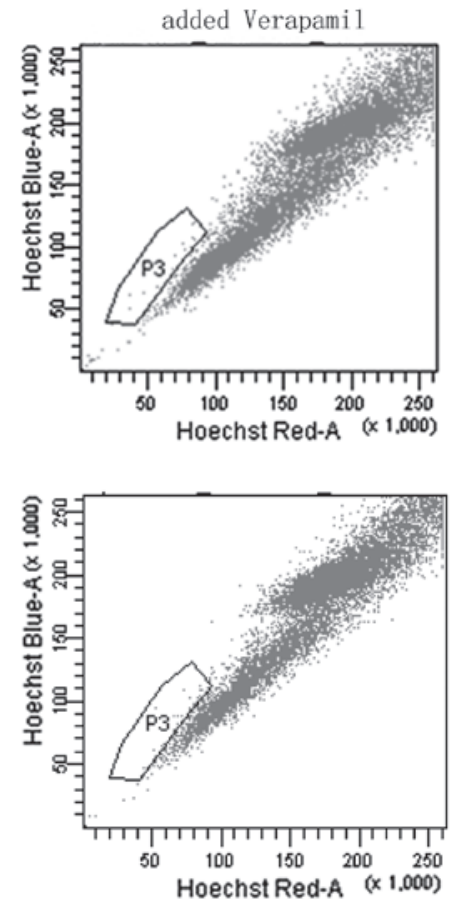

Figure 7. FACS analysis of (A) 5-Fu-treated and (B) parent MC3 cells stained with Hoechst 33342. The ratio of side population cells in the 5-Fu-treated and MC3 cells was $8.3 \pm 0.2$ and 2.03 $\pm 0.25 \%$, respectively. FACS, fluorescence-activated cell sorting; 5-Fu, 5-fluorouracil.

formed spheroids, and chemotherapy may improve the ratio of the formation of spheroids.

SP cell assays. SP flow cytometry has previously been used to enrich cancer stem cells (CSCs) from various cancer cell lines and primary tumors (22-24). SP cells do not fluoresce under the dual wavelength parameters of FACS as they are able to efflux Hoechst 33342 by adenosine triphospate-binding cassette transporters $(21,25-29)$. In the SP assays, SP cells were located in the area of weak fluorescence and the ratio of SP to 5-Fu-treated cells was higher compared with MC3 cells. These data strongly indicated that chemotherapy may significantly increase the number of CSL-cells in MC3 cells (Fig. 7).

\section{Discussion}

Previous studies have identified CSL-cells within tumors and that the injection of CSL-cells into nude mice induces the development of tumors. CSL-cells are considered to be comparable to normal tissue stem cells as they possess the ability to divide asymmetrically and symmetrically, and undergo multilineage differentiation $(30,31)$. Similar to the activity of normal stem cells in the maintenance of tissue architecture, CSL-cells are regarded as a resource of tumor formation, progression, recurrence and drug resistance $(11,32)$. CSL-cells are able to self-renew and differentiate into a diverse range of cells that form tumor masses $(33,34)$. CSL-cells have a stronger resistance to traditional treatments, such as chemotherapy and radiation, compared with other types of tumor cells due to their high expression of drug resistant transporter proteins (such as ABC) $(35-37)$, DNA repair enzymes $(38,39)$ and anti-apoptotic proteins (40-42).
The present study indicated that the CSC phenotype may be induced by 5 -Fu as cancer cells are able to acquire a stemness state, which is characterized by the increased stemness gene expression of Oct4. Oct4 is a typical stem-cell associated gene (43) and may be able to reprogram adult cells into induced pluripotent stem cells (iPS) $(44,45)$. Despite the transcription factors of c-Myc, kruppel-like factor 4 and NANOG, Oct4 is an important gene as its expression is significant in the production of iPS $(44,46,47)$. Previous studies identified a high expression of Oct4 in human embryonic stem cells compared with differentiated tissues and a high expression in CSL-cells compared with other types of cancer cells $(18,48,49)$. In certain cell lines, the increased expression of Oct4 results in enhanced stemness and acquisition of a stem cell-like phenotype $(50,51)$, which is associated with an increase in sphere formation and resistance to chemotherapy and radiotherapy. Knockdown of Oct4 may increase the sensitivity to chemotherapy and radiotherapy due to the restriction of the factors that lead to self-renewal. Therefore, the expression of Oct 4 is important in the identification of CSL-cells.

As a type of transmembrane glycoprotein, CD44 is widely distributed on the cell surface of lymphocytes and fibroblasts (52). CD44 is predominantly involved in specific adhesion processes, such as cell-cell and cell-matrix. Thus, CD44 may be used as a surface marker of CSL-cells. In addition to breast cancer (3), CD44 was considered to be a CSL-cell marker in ovarian (53), prostate (54) and pancreatic cancer (10), and head and neck squamous cell carcinoma (55).

The present study demonstrated that the expression of Oct4 and CD44 increased following treatment with 5-Fu, particularly Oct4 expression in 5-Fu-treated cells, which was markedly higher compared with the parent MC3 cells. These findings were consistent with the increased stem cell-like 
phenotype, as the cloning ratio of the cells in the soft agarose increased from $9.14 \pm 0.747$ to $33.47 \pm 1.30 \%$. To examine this further, the 5-Fu-treated cells were cultured under stem cell culture conditions, which were selective for CSL-cell enrichment. The results indicated that chemotherapy was associated with a significant increase in sphere-formation ability, reflecting a greater self-renewal and proliferation ability of the 5-Fu-treated cells; furthermore, no difference in morphology was observed between the two types of spheroids. In addition, the 5-Fu-treated cells grew faster, reaching the plateau phase more rapidly than the parent MC3 cells in the MTT assays. These findings were consistent with previous studies, demonstrating that the drug resistance of tumor cells is associated with CSL-cells in tumors $(17,56,57)$.

Over the past century, chemotherapy has been used extensively as a curative or adjuvant cancer treatment, particularly for metastatic tumors. However, the majority of human malignancies, including MEC, are resistant to this important therapeutic method. Resistance to chemotherapy is the primary obstacle for patient survival, particularly for those with metastatic tumors (58). In the present study, chemotherapy induced stem cell-like properties, such as sphere formation, clone formation and stemness-related gene expression, demonstrating that chemotherapy may enrich CSL-cells in the MC3 cell line. To further explore the number of CSL-cells in the 5-Fu-treated MC3 cells, flow cytometry using Hoechst 33342 dye exclusion was performed to isolate the SP cells that were enriched in CSCs. Notably, the drug-treated cells exhibited a higher percentage of SP cells compared with the parent MC3 cells; the CSC component in the MC3 cell line increased from 2 to $8 \%$ of the total cell population, indicating that they were more enriched for the CSC phenotype.

In conclusion, CSL-cells are considered to be a cause of tumors due to their similar characteristics to stem cells (self-renewal and multilineage differentiation). The present study indicated that 5-Fu may induce MC3 cells into a stem-like phenotype and that the remaining CSL-cells of MEC following chemotherapy were significant in tumor recurrence, as well as in promoting tumor survival. These findings demonstrated the mechanisms involved in the resistance of cancer cells to chemotherapy and implied that targeting CSL-cells may improve the efficacy of chemotherapy.

\section{Acknowledgements}

The present study was supported by the National Natural Science Foundation of China (grant nos. 30973345 and 81172578).

\section{References}

1. Spiro RH, Huvos AG, Berk R and Strong EW: Mucoepidermoid carcinoma of salivary gland origin. A clinicopathologic study of 367 cases. Am J Surg 136: 461-468, 1978.

2. Bonnet D and Dick JE: Human acute myeloid leukemia is organized as a hierarchy that originates from a primitive hematopoietic cell. Nat Med 3: 730-737, 1997.

3. Al- Hajj M, Wicha MS, Benito-Hernandez A, Morrison SJ and Clarke MF: Prospective identification of tumorigenic breast cancer cells. Proc NatI Acad Sci USA 100: 3983-3988, 2003.
4. Lapidot T, Sirard C, Vormoor J, et al: A cell initiating human acute myeloid leukaemia after transplantation into SCID mice. Nature 367: 645-648, 1994.

5. Liu S, Dontu G and Wicha MS: Mammary stem cells, self-renewal pathways, and carcinogenesis. Breast Cancer Res 7: 86-95, 2005.

6. Singh SK, Hawkins C, Clarke ID, et al: Identification of human brain tumour initiating cells. Nature 432: 396-401, 2004.

7. Galli R, Binda E, Orfanelli U, et al: Isolation and characterization of tumorigenic, stem-like neural precursors from human glioblastoma. Cancer Res 64: 7011-7021, 2004.

8. Hemmati HD, Nakano I, Lazareff JA, Masterman-Smith M, Geschwind DH, Bronner-Fraser M and Kornblum HI: Cancerous stem cells can arise from pediatric brain tumors. Proc Natl Acad Sci USA 100: 15178-15183, 2003.

9. Chiba T, Kita K, Zheng YW, et al: Side population purified from hepatocellular carcinoma cells harbors cancer stem cell-like properties. Hepatology 44: 240-251, 2006.

10. Li C, Heidt DG, Dalerba P, et al: Identification of pancreatic cancer stem cells. Cancer Res 67: 1030-1037, 2007.

11. O'Brien CA, Pollett A, Gallinger S and Dick JE: A human colon cancer cell capable of initiating tumour growth in immunodeficient mice. Nature 445: 106-110, 2007.

12. Ricci-Vitiani L, Lombardi DG, Pilozzi E, Biffoni M, Todaro M, Peschle $C$ and De Maria R: Identification and expansion of human colon-cancer-initiating cells. Nature 445: 111-115, 2007.

13. Fang D, Nguyen TK, Leishear K, et al: A tumorigenic subpopulation with stem cell properties in melanomas. Cancer Res 65: 9328-9337, 2005

14. Collins AT, Berry PA, Hyde C, Stower MJ and Maitland NJ: Prospective identification of tumorigenic prostate cancer stem cells. Cancer Res 65: 10946-10951, 2005.

15. Gibbs CP, Kukekov VG, Reith JD, et al: Stem-like cells in bone sarcomas: implications for tumorigenesis. Neoplasia 7: 967-976, 2005.

16. Beachy PA, Karhadkar SS and Berman DM: Tissue repair and stem cell renewal in carcinogenesis. Nature 432: 324-331, 2004.

17. Dean M, Fojo T and Bates S: Tumour stem cells and drug resistance. Nat Rev Cancer 5: 275-284, 2005.

18. Kamstrup MR, Gniadecki R and Skovgaard GL: Putative cancer stem cells in cutaneous malignancies. Exp Dermatol 16: 297-301, 2007.

19. Setoguchi T, Taga T and Kondo T: Cancer stem cells persist in many cancer cell lines. Cell Cycle 3: 414-415, 2004.

20. Sunyou Z, Yi Z, Xu D and Xinghao Z: The relationship between oral cancer HSP-70 expression and drug sensitivity test in vitro. Shiyong Yixue Zazhi 22: 1839-1841, 2006 (In Chinese).

21. Goodell MA, Brose K, Paradis G, Conner AS and Mulligan RC: Isolation and functional properties of murine hematopoietic stem cells that are replicating in vivo. J Exp Med 183: 1797-1806, 1996.

22. Kondo T, Setoguchi T and Taga T: Persistence of a small subpopulation of cancer stem-like cells in the C6 glioma cell line. Proc Natl Acad Sci USA 101: 781-786, 2004.

23. Hirschmann-Jax C, Foster AE, Wulf GG, et al: A distinct 'side population' of cells with high drug efflux capacity in human tumor cells. Proc Natl Acad Sci USA 101: 14228-14233, 2004.

24. Chen JS, Pardo FS, Wang-Rodriguez J, et al: EGFR regulates the side population in head and neck squamous cell carcinoma. Laryngoscope 116: 401-406, 2006.

25. Zhou S, Schuetz JD, Bunting KD, et al: The ABC transporter $\mathrm{Bcrp1/ABCG2}$ is expressed in a wide variety of stem cells and is a molecular determinant of the side-population phenotype. Nat Med 7: 1028-1034, 2001.

26. Robinson SN, Seina SM, Gohr JC, Kuszynski CA and Sharp JG: Evidence for a qualitative hierarchy within the Hoechst-33342 'side population' (SP) of murine bone marrow cells. Bone Marrow Transplant 35: 807-818, 2005.

27. Hadnagy A, Gaboury L, Beaulieu R and Balickin D: SP analysis may be used to identify cancer stem cell populations. Exp Cell Res 312: 3701-3710, 2006.

28. Wu C and Alman BA: Side population cells in human cancers. Cancer Lett 268: 1-9, 2008.

29. Hirschmann-Jax C, Foster AE, Wulf GG, Goodwell MA and Brenner MK: A distinct 'side population' of cells in human tumor cells: Implications for tumor biology and therapy. Cell Cycle 4: 203-205, 2005.

30. Jordan CT, Guzman ML and Noble M: Cancer stem cells. N Engl J Med 355: 1253-1261, 2006.

31. Visvader JE and Lindeman GJ: Cancer stem cells in solid tumours: accumulating evidence and unresolved questions. Nat Rev Cancer 8: 755-768, 2008. 
32. Loebinger MR, Giangreco A, Groot KR, et al: Squamous cell cancers contain a side population of stem-like cells that are made chemosensitive by ABC transporter blockade. Br J Cancer 98 380-387, 2008

33. Reya T, Morrison SJ, Clarke MF and Weissman IL: Stem cells, cancer, and cancer stem cells. Nature 414: 105-111, 2001.

34. Woodruff MF: Cellular heterogeneity in tumours. Br J Cancer 47: 589-594, 1983

35. Haraguchi $\mathrm{N}$, Ishii $\mathrm{H}$, Mimori $\mathrm{K}$, et al: $\mathrm{CD} 13$ is a therapeutic target in human liver cancer stem cells. J Clin Invest 120 3326-3339, 2010

36. Gottesman MM, Fojo T and Bates SE: Multidrug resistance in cancer: role of ATP-dependent transporters. Nat Rev Cancer 2: 48-58, 2002

37. Doyle LA, Yang W, Abruzzo LV, Krogmann T, Gao Y, et al: A multidrug resistance transporter from human MCF-7 breast cancer cells. Proc Natl Acad Sci USA 95: 15665-15670, 1998.

38. Martin LP, Hamilton TC and Schilder RJ: Platinum resistance: the role of DNA repair pathways. Clin Cancer Res 14: 1291-1295, 2008.

39. Zhang M, Atkinson RL and Rosen JM: Selective targeting of radiation resistant tumor-initiating cells. Proc Natl Acad Sci USA 107: 3522-3527, 2010.

40. Madjd Z, Mehrjerdi AZ, Sharifi AM, Molanaei S, Shahzadi SZ and Asadi-Lari M: CD44+ cancer cells express higher levels of the anti-apoptotic protein Bcl-2 in breast tumours. Cancer Immun 9: 4, 2009.

41. Zobalova R, McDermott L, Stantic M, Prokopova K, Dong LF and Neuzil J: CD133-positive cells are resistant to TRAIL due to up-regulation of FLIP. Biochem Biophys Res Commun 373 $567-571,2008$

42. Liu G, Yuan X, Zeng Z, et al: Analysis of gene expression and chemoresistance of CD133+ cancer stem cells in glioblastoma. Mol Cancer 5: 67, 2006.

43. Pan GJ, Chang ZY, Scholer HR and Pei D: Stem cell pluripotency and transcription factor Oct4. Cell Res 12: 321-329, 2002

44. Takahashi $\mathrm{K}$ and Yamanaka S: Induction of pluripotent stem cells from mouse embryonic and adult fibroblast cultures by defined factors. Cell 126: 663-676, 2006.

45. Kim JB, Sebastiano V, Wu G, et al: Oct4-induced pluripotency in adult neural stem cells. Cell 136: 411-419, 2009.

46. Yu J, Vodyanik MA, Smuga-Otto K, et al: Induced pluripotent stem cell lines derived from human somatic cells. Science 318: $1917-1920,2007$
47. Kim JB, Zaehres H, Wu G, et al: Pluripotent stem cells induced from adult neural stem cells by reprogramming with two factors. Nature 454: 646-650, 2008

48. Jones TD, Ulbright TM, Eble JN, Baldridge LA and Cheng L: OCT-4 staining in testicular tumors: a sensitive and specific marker for seminoma and embryonal carcinoma. Am J Surg Pathol 28: 935-940, 2004.

49. Tai MH, Chang CC, Kiupel M, Webster JD, Olson LK and Trosko JE: Oct4 expression in adult human stem cells: evidence in support of the stem cell theory of carcinogenesis. Carcinogenesis 26: 495-502, 2005.

50. Beltran AS, Rivenbark AG, Richardson BT, et al: Generation of tumor-initiating cells by exogenous delivery of OCT4 transcription factor. Breast Cancer Res 13: R94, 2011.

51. Ghisolfi L, Keates AC, Hu X, Lee DK and Li CJ: Ionizing radiation induces stemness in cancer cells. PLoS One 7: e43628, 2012.

52. Haynes BF, Liao HX and Patton KL: The transmembrane hyaluronate receptor (CD44): multiple functions, multiple forms. Cancer Cells 3: 347-350, 1991.

53. Zhang S, Balch C, Chan MW, et al: Identification and characterization of ovarian cancer-initiating cells from primary human tumors. Cancer Res 68: 4311-4320, 2008.

54. Hurt EM, Kawasaki BT, Klarmann GJ, Thomas SB and Farrar WL: CD44+ CD24(-) prostate cells are early cancer progenitor/stem cells that provide a model for patients with poor prognosis. Br J Cancer 98: 756-765, 2008.

55. Pries R, Witrkopf N, Trenkle T, Nitsch SM and Wollenberg B: Potential stem cell marker CD44 is constitutively expressed in permanent cell lines of head and neck cancer. In Vivo 22: 89-92, 2008.

56. Kawabata S, Oka M, Soda H, et al: Expression and functional analyses of breast cancer resistance protein in lung cancer. Clin Cancer Res 9: 3052-3057, 2003.

57. Al-Hajj M, Becker MW, Wicha M, Weissman I and Clarke MF: Therapeutic implications of cancer stem cells. Curr Opin Genet Dev 14: 43-47, 2004.

58. Dy GK, Hobday TJ, Nelson G, et al: Long-term survivors of metastatic colorectal cancer treated with systemic chemotherapy alone: a North Central Cancer Treatment Group review of 3811 patients, N0144. Clin Colorectal Cancer 8: 88-93, 2009. 